ORNL/TM-2002/118

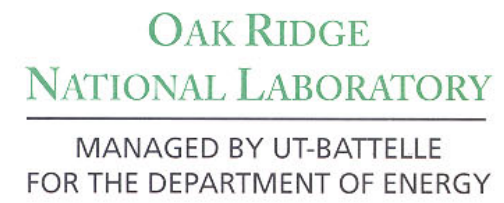

\title{
Plutonium Production Using Natural Uranium From the Front-End of the Nuclear Fuel Cycle
}

\author{
C. V. Parks \\ B. D. Murphy \\ L. M. Petrie \\ C. M. Hopper
}




\section{DOCUMENT AVAILABILITY}

Reports produced after January 1, 1996, are generally available free via the U.S. Department of Energy (DOE) Information Bridge:

Web site: http://www.osti.gov/bridge

Reports produced before January 1, 1996, may be purchased by members of the public from the following source:

National Technical Information Service

5285 Port Royal Road

Springfield, VA 22161

Telephone: 703-605-6000 (1-800-553-6847)

TDD: $703-487-4639$

Fax: 703-605-6900

E-mail: info@ ntis.fedworld.gov

Web site: http://www.ntis.gov/support/ordernowabout.htm

Reports are available to DOE employees, DOE contractors, Energy Technology Data Exchange (ETDE) representatives, and International Nuclear Information System (INIS) representatives from the following source:

Office of Scientific and Technical Information

P.O. Box 62

Oak Ridge, TN 37831

Telephone: $865-576-8401$

Fax: 865-576-5728

E-mail: reports@adonis.osti.gov

Web site: http://www.osti.gov/contact.html

This report was prepared as an account of work sponsored by an agency of the United States Government. Neither the United States government nor any agency thereof, nor any of their employees, makes any warranty, express or implied, or assumes any legal liability or responsibility for the accuracy, completeness, or usefulness of any information, apparatus, product, or process disclosed, or represents that its use would not infringe privately owned rights. Reference herein to any specific commercial product, process, or service by trade name, trademark, manufacturer, or otherwise, does not necessarily constitute or imply its endorsement, recommendation, or favoring by the United States Government or any agency thereof. The views and opinions of authors expressed herein do not necessarily state or reflect those of the United States Government or any agency thereof. 


\title{
Plutonium Production Using Natural Uranium From the Front-End of the Nuclear Fuel Cycle
}

\author{
C. V. Parks, B. D. Murphy, L. M. Petrie, and C. M. Hopper \\ Oak Ridge National Laboratory \\ Oak Ridge, TN 37831-6370 \\ parkscv@ornl.gov \\ (865) 574-5280
}

Date Published: September 2002

Prepared by the

OAK RIDGE NATIONAL LABORATORY

Oak Ridge, Tennessee 37831 USA

managed by

UT-Battelle, LLC

for the

U.S. DEPARTMENT OF ENERGY

under contract DE-AC05-00OR22725 



\section{CONTENTS}

\section{Page}

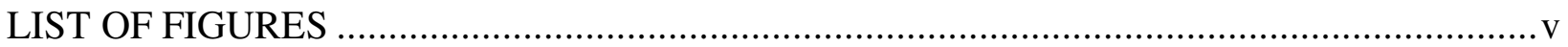

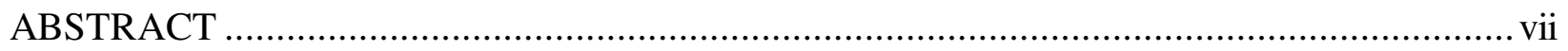

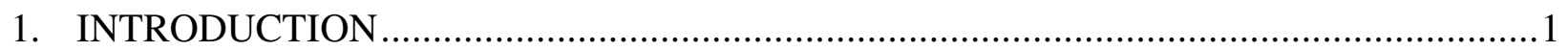

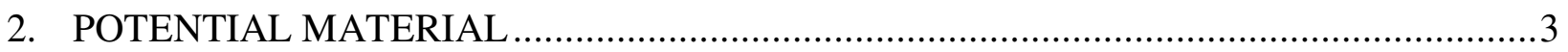

3. ANALYSIS METHODS AND REACTOR MODELS ............................................

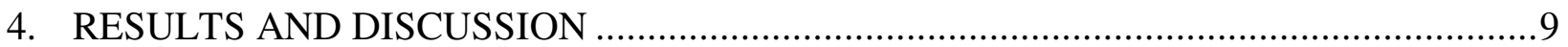

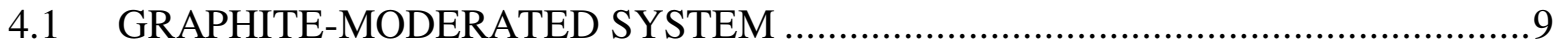

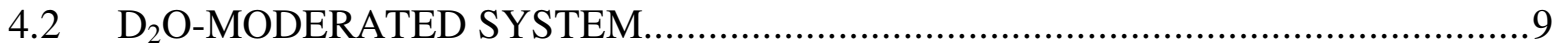

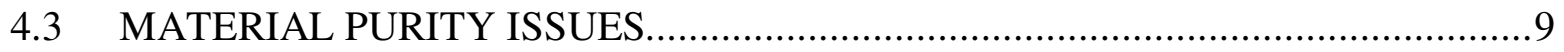

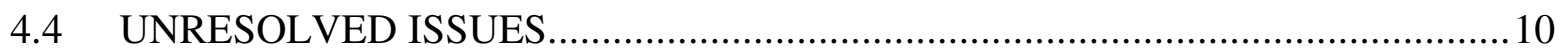

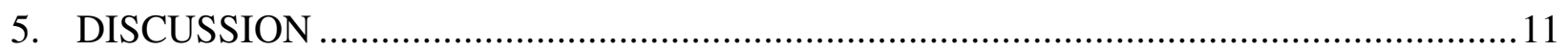

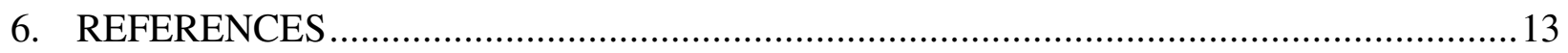




\section{LIST OF FIGURES}

Figure $\quad$ Page

Fig. 1. Reactor system effective neutron multiplication $\left(k_{e f f}\right)$ as a function of fuel mass............6 


\section{ABSTRACT}

This report explores the potential for producing weapons-grade plutonium using conventional industrial resources, oxides of natural uranium (namely $\mathrm{UO}_{3}$ ), and either heavy water or reactor-grade graphite. Using established codes and data for nuclear analysis, it is demonstrated that physics-based reactor models capable of producing kilogram quantities of weapons-grade plutonium can be readily conceived. The basic assumptions and analysis approach are discussed together with the results of the analysis. 


\section{INTRODUCTION}

A question has been raised as to whether the uranium oxides that may be produced during the conversion process (e.g., $\mathrm{UO}_{3}$ and $\mathrm{U}_{3} \mathrm{O}_{8}$ ) are of suitable composition and purity to be used for reactor fuel fabrication. The purpose of this report is to explore the technical feasibility for using these natural uranium compounds as reactor fuel for the production of weapons-grade plutonium. This report and the analyses discussed focus primarily on the physics issues and address whether there are limitations is using these oxides as fuel. 


\section{POTENTIAL MATERIAL}

The fuel cycle begins with mining and milling operations that produce uranium ore concentrate. This ore is converted to $\mathrm{U}_{3} \mathrm{O}_{8}$ that is then dissolved with nitric acid to form uranyl nitrate, which is then purified for the production of $\mathrm{UO}_{3} . \mathrm{UO}_{3}$ is a starting point for the manufacture of various forms of uranium fuel: it may be used to produce $\mathrm{UO}_{2}$ containing natural uranium $\left(0.71 \%{ }^{235} \mathrm{U}\right)$; it might be used to produce uranium hexafluoride for processes that enrich the isotopic content of ${ }^{235} \mathrm{U}$ uranium; and it can also serve as a starting point for the production of uranium metal. It is possible to build a reactor using natural uranium as the fuel and either graphite or heavy water $\left(\mathrm{D}_{2} \mathrm{O}\right)$ as the moderator. The Oak Ridge Graphite Reactor and the CANDU reactor designs are two well-known examples. The use of natural uranium avoids the necessity of a uranium enrichment process.

The uranium ore concentrate or yellowcake is not a very pure substance. But, the dissolution, filtering, solvent extraction, and evaporation processes in the production of uranyl nitrate result in a reasonably pure uranium compound such as specified by the American Society for Testing and Materials standards.., 2 Thus, a chemically pure form of natural uranium is available as uranyl nitrate or $\mathrm{UO}_{3}$ prior to introduction of safeguards. Because of the high neutron-capture cross section for ${ }^{14} \mathrm{~N}$, uranyl nitrate is not a likely candidate as a fuel for a natural uranium reactor. However, pure $\mathrm{UO}_{3}$ could potentially be used as a ready source for fuel in a specially designed plutonium production reactor; thus raising a potential diversion concern.

A reactor with natural uranium as fuel is only possible if the fission neutrons can be efficiently slowed to thermal energies in a moderator that has little, if any parasitic absorption of the neutrons. Because of parasitic neutron absorption by hydrogen, natural uranium with a light water moderator cannot maintain a critical assembly (i.e., a system neutron multiplication factor, $k$, equal to unity). As indicated previously, a natural uranium-fueled reactor must use either high-purity graphite or heavy water as the moderating material. Carbon and deuterium, the principal neutron moderating constituents in graphite and heavy water, respectively, each have much lower parasitic neutron-absorption cross sections than hydrogen.

In a reactor fueled with natural uranium, slightly more than $99 \%$ will be ${ }^{238} \mathrm{U}$ (there may be small amounts of ${ }^{234} \mathrm{U}$ ). During reactor operation, neutron capture by the ${ }^{238} \mathrm{U}$ results in the production of ${ }^{239} \mathrm{Pu}$ - the main fissile isotope of plutonium that could be removed from the spent fuel for use in weapons manufacture. However, another important plutonium isotope is ${ }^{240} \mathrm{Pu}$. This latter isotope of plutonium is also produced during reactor operation by neutron capture on the ${ }^{239} \mathrm{Pu}$. Furthermore, ${ }^{240} \mathrm{Pu}$ is subject to spontaneous fission, thus producing neutrons, and for this reason it is a hindrance to the design of an efficient weapon. Thus, if one's intent is to produce weapons-grade plutonium, it is necessary to remove the irradiated fuel after only a small amount of burnup so as to ensure that the relative concentration of ${ }^{240} \mathrm{Pu}$ is low. For the analyses performed in this report, the target limit for ${ }^{240} \mathrm{Pu}$ production was $5 \%$ of the total plutonium. 


\section{ANALYSIS METHODS AND REACTOR MODELS}

To explore the potential for producing weapons-grade plutonium using materials from the early portion of the fuel cycle, scoping analyses were performed assuming a reactor system containing natural uranium in the form of $\mathrm{UO}_{3}$ and graphite or $\mathrm{D}_{2} \mathrm{O}$ as the moderator. These analyses were performed to help indicate the feasibility for producing weapons-grade plutonium, not to identify or resolve all the complex issues that must be considered in the design and construction of an operating reactor.

The SCALE code system 3 was used to perform the nuclear analysis. The CSAS/KENO analysis sequence from SCALE was used to perform three-dimensional static physics analyses to establish an initial reactor configuration with sufficient excess reactivity to maintain reactor operations throughout irradiation. The reactor operation was simulated using the SAS2H/ORIGEN-S sequence of SCALE. This sequence uses an approximate neutronic model to provide cross-section information for the depletion/decay portion of the analysis. The SAS2H/ORIGEN-S sequence has been demonstrated to be a valid method for predicting spent fuel inventories from commercial and research reactor fuel.

Since the goal was to explore feasibility, little effort was expended on evaluating various possible reactor designs. Established experience led to somewhat arbitrary assumption of a reactor with a square-pitch geometry of aluminum-clad, annular fuel rods interspersed in the moderating medium. Annular rods are a requirement in the graphite system because they provide demands for a gas coolant to flow. The gas was assumed to be air for the physics analysis but a more ideal heat transfer material could be used with no impact on the results. To allow for cooling, the annular fuel rods were assumed to have an inner diameter of $2.54 \mathrm{~cm}$ and an outer diameter of $5.08 \mathrm{~cm}$. The CSAS/KENO sequence was then used to help determine the rod-to-rod pitch that yielded the highest neutron multiplication factor for an infinite system $\left(k_{\text {inf }}\right)$. For the graphite-moderated reactor, the optimum rod-to-rod pitch with this fuel thickness is $18.26 \mathrm{~cm}$. The outer fuel rod radius was then varied to determine the optimum fuel thickness while maintaining the interstitial moderator thickness associated with the rod-to-rod pitch previously obtained. The initial estimate of $5.08 \mathrm{~cm}$ turned out to be very close to the optimum $(5.35 \mathrm{~cm})$ fuel thickness. Using these optimum values for fuel rod size and spacing, another series of CSAS/KENO calculations were performed to determine the reactor size with enough excess reactivity $(k-1)$ to operate the reactor for the duration needed to allow plutonium production. A 2-m-thick graphite reflector was assumed to surround the finite reactor core. Figure 1 shows a plot of the effective neutron multiplication factor $\left(k_{\text {eff }}\right)$ for the reactor system as a function of the fuel mass. A reactor with about $120 \mathrm{t}(120,000 \mathrm{~kg})$ of fuel provided sufficient excess reactivity to assure a critical configuration could be maintained during a reasonable irradiation cycle. Using this reactor model with $\mathrm{SAS} 2 \mathrm{H}$, plutonium production rates and plutonium quality were then estimated.

A second set of calculations was carried out using $\mathrm{D}_{2} \mathrm{O}$ as the moderator, with $\mathrm{UO}_{3}$ still assumed as the fuel. The same annular fuel rod design was chosen, and the optimum rod-to-rod spacing and fuel thickness was determined. For $\mathrm{D}_{2} \mathrm{O}$, however, there is a broad range in pitch where conditions are essentially equivalent. A value of $25.04 \mathrm{~cm}$ was selected for the rod-to-rod pitch. Figure 1 shows that the excess reactivity is much higher using $\mathrm{D}_{2} \mathrm{O}$ as the moderator and 
assuming a 2-m-thick $\mathrm{D}_{2} \mathrm{O}$ reflector. A reactor with $20 \mathrm{t}(20,000 \mathrm{~kg})$ of fuel was used although Fig. 1 illustrates that a smaller reactor could have been selected. The increased reactivity of the $\mathrm{D}_{2} \mathrm{O}$-moderated system is further enhanced when $\mathrm{D}_{2} \mathrm{O}$ is used as the coolant in the center of the annulus. The larger reactivity in the $\mathrm{D}_{2} \mathrm{O}$ case allows a smaller reactor and better heat transfer to the $\mathrm{D}_{2} \mathrm{O}$ should allow a higher power level, thereby increasing the plutonium production rate. However, the neutron energy spectrum in the $\mathrm{D}_{2} \mathrm{O}$ reactor is more thermal than for the graphitemoderated system and this enhanced thermalization raises the capture rate for neutrons in ${ }^{239} \mathrm{Pu}$ and increases the production of ${ }^{240} \mathrm{Pu}$. Thus, the plutonium being produced in the reactor will reach the imposed limit of $5 \mathrm{wt} \%{ }^{240} \mathrm{Pu}$ more rapidly than with a graphite-moderated reactor.

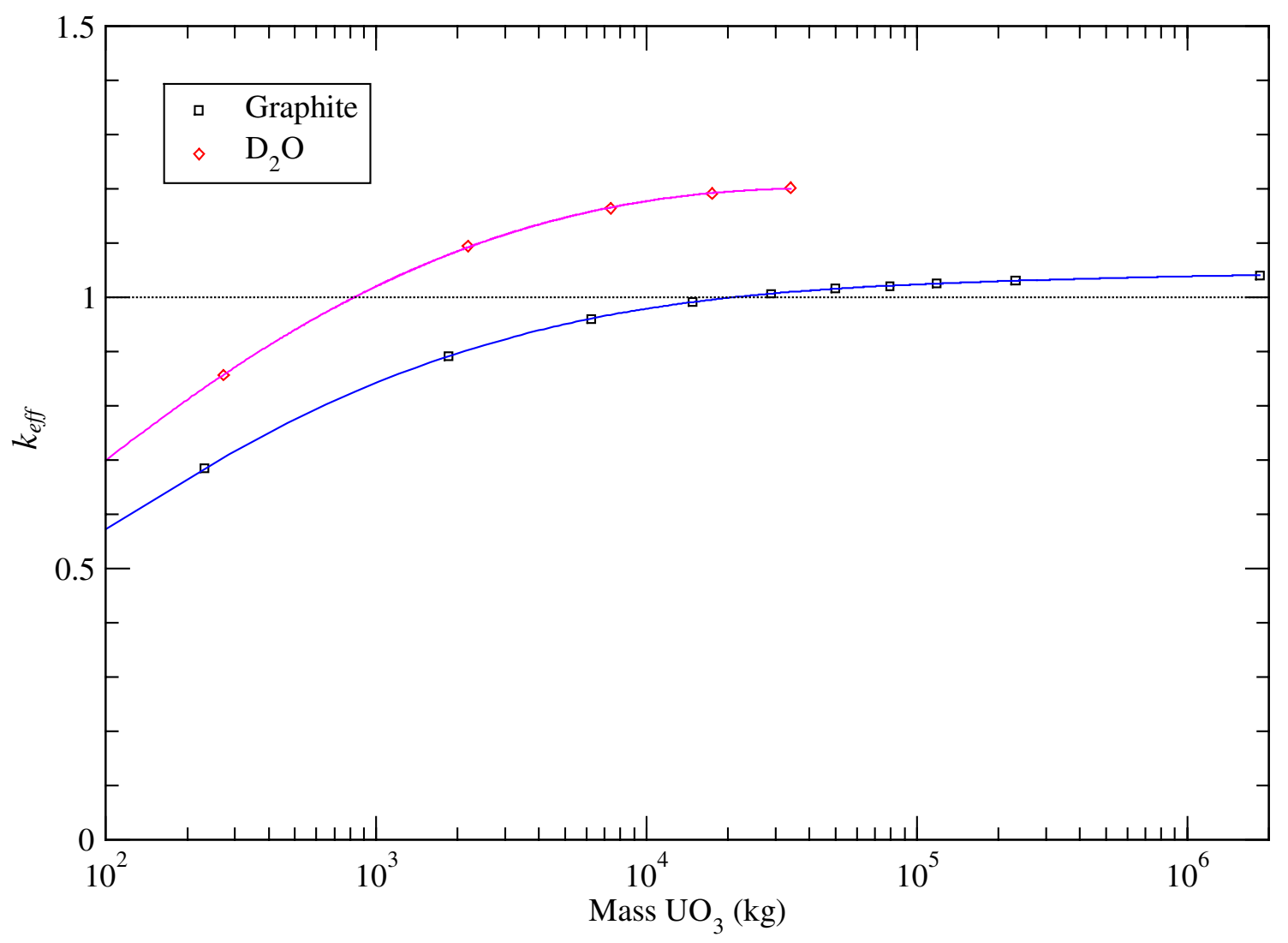

Fig. 1. Reactor system effective neutron multiplication $\left(k_{e f f}\right)$ as a function of fuel mass. 
It was noted that a reactor system based on uranyl nitrate would not likely maintain a chain reaction. As a check, a final set of calculations was performed using $\mathrm{UO}_{2}\left(\mathrm{NO}_{3}\right)_{2}$ as the fuel, and with $\mathrm{D}_{2} \mathrm{O}$ as the moderator. The $k_{\text {inf }}$ value was less than 0.8 for all cases investigated. While more careful design might raise that value somewhat, it is not reasonable to expect it could ever approach 1.0, much less have sufficient excess reactivity to maintain reactor operation. The thermal absorption cross section for nitrogen is too large to enable a critical system using natural uranium. Finally, a few checks were performed with $\mathrm{UF}_{4}$ as fuel. From a reactivity standpoint $\mathrm{UF}_{4}$ turns out to be nearly equivalent to $\mathrm{UO}_{3}$. Therefore, any reactor using $\mathrm{UO}_{3}$ could probably be made critical with $\mathrm{UF}_{4}$; however, the relative stability of $\mathrm{UO}_{3}$ compared to $\mathrm{UF}_{4}$ when they are heated, is an issue that was not investigated. 


\section{RESULTS AND DISCUSSION}

\subsection{GRAPHITE-MODERATED SYSTEM}

The preliminary calculations performed show that a reactor, large enough to produce significant amounts of weapons-grade plutonium, would require on the order of $120 \mathrm{t}$ of $\mathrm{UO}_{3}$ (natural uranium) together with $3300 \mathrm{t}$ of reactor-grade graphite as moderator. The reactor core would be a $7.3 \mathrm{~m}$ cube surrounded by a 2-m-thick graphite reflector. Such a reactor could produce $40 \mathrm{~kg}$ of ${ }^{239} \mathrm{Pu}$ with less than $5 \%{ }^{240} \mathrm{Pu}$ over a period of two years while operating at a power level of $64 \mathrm{MW}$. Increasing the power level would shorten the production time but likely lead to greater difficulties relative to heat dissipation and fuel integrity. A lower power level might be beneficial to lower the mechanical and thermal stress on the fuel and clad. As an approximation, it appears that such a reactor concept could produce roughly $26 \mathrm{~g}$ of ${ }^{239} \mathrm{Pu}$ per month per megawatt.

\section{2 $\mathrm{D}_{2} \mathrm{O}$-MODERATED SYSTEM}

Preliminary analyses indicate that there are many variables to consider in designing an optimal system with heavy water as the moderator. However, the goal of this report was not to optimize but to demonstrate potential feasibility. The analyses demonstrate that with a $2.5-\mathrm{m}$ cubic core containing $20 \mathrm{t}$ of $\mathrm{UO}_{3}$ (natural uranium), one could produce about $11 \mathrm{~kg}$ of ${ }^{239} \mathrm{Pu}$ (with less than $5 \%{ }^{240} \mathrm{Pu}$ ) in about 30 days using an assumed power level of $65 \mathrm{MW}$. The assumed reactor model would require $300 \mathrm{t}$ of $\mathrm{D}_{2} \mathrm{O}$. Such a reactor would have a rough production rate of $170 \mathrm{~g}$ of ${ }^{239} \mathrm{Pu}$ per month per megawatt.

From a neutronic perspective, the $\mathrm{D}_{2} \mathrm{O}$-moderated reactor provides a wide range of plausible reactor parameters and designs that would achieve weapons-grade plutonium production. This wide range of variability makes it more difficult to determine the optimum operating conditions. For instance, it is not clear that maximizing the $k_{\text {eff }}$ value is the optimal approach for $\mathrm{D}_{2} \mathrm{O}$ because this will likely thermalize the neutron spectrum thereby increasing the burnup of ${ }^{239} \mathrm{Pu}$ and increasing the production of ${ }^{240} \mathrm{Pu}$. However, it is clear that the basic capability to produce weapons-grade plutonium can be obtained with the $\mathrm{D}_{2} \mathrm{O}$-moderated system; the production rates will vary depending on the parameters selected.

\subsection{MATERIAL PURITY ISSUES}

The analyses reported above assumed that the $\mathrm{UO}_{3}, \mathrm{D}_{2} \mathrm{O}$, and graphite were pure with no contaminants that would impact the neutronic performance or the plutonium production. The ASTM standards ${ }^{1,2}$ provide guidelines on impurity levels for uranyl nitrate and uranium oxides that are readily achievable with known chemical processes. The impurity levels in these standards would have no impact on the neutronic performance of any conceived reactor model. Similarly, very pure graphite is needed because "normal" graphite contains minute amounts of boron. One of the boron isotopes $\left({ }^{10} \mathrm{~B}\right)$ has an extremely high neutron-capture cross section, 
making regular graphite unacceptable as a reactor moderator. Reactor-grade graphite, once obtained, would not be readily contaminated. In contrast $\mathrm{D}_{2} \mathrm{O}$, over time, can become contaminated with $\mathrm{H}_{2} \mathrm{O}$. The circumstances that cause $\mathrm{D}_{2} \mathrm{O}$ contamination and the related quantity of the contamination are not addressed in this report. However, it is assumed that a well-sealed reactor could readily maintain an $\mathrm{H}_{2} \mathrm{O}$ contamination less than $1 \mathrm{wt} \%$. From a neutronic perspective, a contamination level of $0.1 \mathrm{wt} \% \mathrm{H}_{2} \mathrm{O}$ would provide a very small impact. A contamination level of $1 \mathrm{wt} \% \mathrm{H}_{2} \mathrm{O}$ would provide a sizable impact on reactivity that would have to be considered in the reactor design. However, as noted from the results of Fig. 1, there is sufficient reactivity margin available in a $\mathrm{D}_{2} \mathrm{O}$-moderated system to readily accommodate anticipated, reasonable contamination levels.

\subsection{UNRESOLVED ISSUES}

There are many additional variables to be considered in determining the detailed design of a production reactor: fuel performance, heat removal, cladding integrity, etc. These issues have not been explicitly addressed in this report, but were considered in a cursory fashion to establish a credible scenario for a production reactor using natural uranium oxides. Fuel fabrication experts at ORNL who are experienced with fabrication of reactor fuel recognize that design of a reactor using $\mathrm{UO}_{3}$ fuel would be a challenge, but are of the opinion that it is technically possible. While $\mathrm{UO}_{3}$ would not be a good fuel material at high temperature, operating the reactor at lower power levels is a potential strategy to mitigate fuel performance, heat dissipation and cladding integrity issues. 


\section{DISCUSSION}

In summary, it would appear that ${ }^{239} \mathrm{Pu}$ could be obtained from material available early in the nuclear fuel cycle. Both graphite and heavy water seem viable as moderator materials. When considered simply in terms of production rate versus uranium investment, the $\mathrm{D}_{2} \mathrm{O}-$ moderated system would seem to be more efficient, although its design contains more complexities from the neutronic perspective. Graphite, on the other hand, may be more preferable for a variety of neutronic reasons. Graphite may also be easier to acquire, transport, and store.

In summary, it is concluded that it is potentially possible to produce weapon-grade plutonium using uranium oxide available early in the fuel cycle. High levels of purity would be required for the fuel and moderator material. Achieving these levels of purity may well be possible given moderate levels of scientific and engineering know-how. 


\section{REFERENCES}

1. Standard Specification for Nuclear-Grade Uranyl Nitrate Solution, ASTM-C788-98, American Society of Testing and Materials (1998).

2. Standard Specification for Sintered Uranium Dioxide Pellets, ASTM-C776-00, American Society of Testing and Materials (2000).

3. SCALE: A Modular Code System for Performing Standardized Computer Analyses for Licensing Evaluation, NUREG/CR-0200, Rev. 6 (ORNL/NUREG/CSD-2/R6), Vols. I, II, and III, May 2000. Available from Radiation Safety Information Computational Center at Oak Ridge National Laboratory as CCC-545. 


\section{DISTRIBUTION}

1. S. M. Bowman, 6011, MS-6370

2. B. L. Broadhead, 6011, MS-6370

3-12. W. C. Carter, 6011, MS-6370

13. R. D. Dabbs, 7964C, MS-6392

14. M. D. DeHart, 6011, MS-6370

15. I. C. Gauld, 6011, MS-6370

16. J. N. Herndon, 4500N, MS-6228

17. D. J. Hill, 4500N, MS-6228

18. C. M. Hopper, 6011, MS-6370

19. B. D. Murphy, 6011, MS-6370
20. C. V. Parks, 6011, MS-6370

21. L. M. Petrie, 6011, MS-6370

22. R. T. Primm III, 7917, MS-6399

23. J. C. Wagner, 6011, MS-6370

24-33. R. M. Westfall, 6011, MS-6370

34. J. M. Whitaker, 1099COM, MS-6486

35. Laboratory Records, $4500 \mathrm{~N}, \mathrm{MS}-6254$

36. Central Research Library, 4500N, MS-6191 
